\title{
FORMAÇÃO EM SAÚDE GRADUASUS: RELATO DE INSERÇÕES INTERDISCIPLINARES EM UMA UNIDADE BÁSICA DE SAÚDE
}

\author{
Ana Clara Zalasik ${ }^{1}$ \\ Maria Catarina Cândido da Silva² \\ Carina Nunes Bossardi ${ }^{3}$ \\ Fabíola Hermes Chesani ${ }^{4}$ \\ Recebido em: 08 abr. 2018 \\ Aceito em: 09 mar. 2019
}

RESUMO: Este trabalho trata-se de um relato de experiência de integração ensino-serviçocomunidade com a implementação do projeto PET- Saúde/GraduaSUS. Teve como objetivo relatar a experiência vivenciada por acadêmicos na relação teoria e prática durante o primeiro ano do curso, tendo em vista a Atenção Primária e a Integralidade em Saúde. Foram realizadas inserções práticas e teóricas em uma Unidade Básica de Saúde de um município do Estado de Santa Catarina. Acredita-se que esse relato trará contribuições significativas para a área da saúde, especialmente no que se refere à formação de profissionais voltados para a atuação no Sistema de Saúde Nacional.

Palavras-chave: Sistema Único de Saúde; Atenção Primária à Saúde; Integralidade em Saúde; Promoção da Saúde.

\section{HEALTH EDUCATION GRADUASUS: REPORT OF INTERDISCIPLINARY}

\section{INSERTIONS IN A BASIC HEALTH UNIT}

ABSTRACT: This work is an account of experience teaching-service-community integration with the implementation of the project PET-GraduaSUS. The purpose of this study was to report on the experience of academics in the relationship between theory and practice during the first year of the course, in view of Primary Care and Health Integrality. Practical and theoretical insertions were made in a Basic Health Unit of a state municipality of Santa Catarina. It is believed that this report will bring significant contributions to the health area, especially regarding the training of professionals focused on the National Health System.

Keywords: Unified Health System; Primary Health Care; Integrality in Health; Health Promotion.

\footnotetext{
${ }^{1}$ Acadêmica do Curso de Graduação em Psicologia da Universidade do Vale do Itajaí (UNIVALI), Itajaí (SC). E-mail para contato: a.nazala@hotmail.com.

2 Acadêmica do Curso de Graduação em Psicologia da Universidade do Vale do Itajaí (UNIVALI), Itajaí (SC). E-mail para contato: mariacatarinacandido@hotmail.com.

3 Professora Dr $^{\mathrm{a}}$ do curso de Psicologia e do Mestrado em Saúde e Gestão do Trabalho da Universidade do Vale do Itajaí (UNIVALI), Itajaí (SC). E-mail para contato: carinabossardi@univali.br.

4 Professora Dra ${ }^{\mathrm{a}}$ do curso de Fisioterapia e do Mestrado em Saúde e Gestão do Trabalho da Universidade do Vale do Itajaí (UNIVALI), Itajaí (SC). E-mail para contato: fabiola.chesani@univali.br.
} 


\section{INTRODUÇÃO}

O Sistema Único de Saúde (SUS), desde sua implementação, em 1990, preza por melhores condições de vida e de saúde para a população como um todo. Para o SUS, para se promover saúde é necessário ampliar as condições de qualidade de vida da população, de alimentação, de trabalho, de educação, de meio ambiente, de saneamento básico, entre outras (BRASIL, 2012). Dessa forma, sob a concepção atual de saúde e, em decorrência das novas formas de produção da saúde, as estratégias não se encontram somente focadas no comportamento individual, indicando, assim, uma compreensão coletiva do processo saúde-doença (VERDI; CAPONI, 2005). Nessa perspectiva, surge o debate sobre o processo de determinação social em saúde.

No modelo da determinação social da saúde o contexto social tem importante impacto no processo saúde-doença. As condições de saúde de um grupo são entendidas a partir de uma análise das condições sociais em que se vive. Nesse processo, são consideradas as determinações biológicas, mas de uma forma mais abrangente e complexa, tendo em vista que tais características passam a ser compreendidas em consideração aos aspectos sociais de vida de cada sujeito (ROCHA; DAVID, 2015).

Para tanto, convém refletir e atuar numa proposta que permita um trabalho conjunto entre educação e saúde. Os trabalhadores da saúde necessitam de uma proposta política e pedagógica que possibilite a formação e a aquisição de habilidades e competências para atuar em decorrência dos princípios do SUS, da concepção atual do processo saúdedoença e das mudanças concernentes a esse processo na contemporaneidade. Em se tratando de formas contemporâneas de entender e produzir saúde, os profissionais precisam, antes de tudo, serem capazes de se tornarem cidadãos críticos tanto no que concerne aos seus direitos e deveres, quanto à produção de práticas voltadas para atender aos usuários de forma integral (AMÂNCIO FILHO, 2004).

Conforme apontam Passos e Carvalho (2015), direito à saúde implica acesso a todo processo que envolve saúde, o que indica a necessidade de defender a universalidade do acesso e a integralidade no cuidado e a equidade das ofertas. Tais princípios serão alcançados levando em consideração a Atenção Básica de Saúde e, nesse sentido, apontase também a importância do trabalho desenvolvido em equipe. Tais indicações podem ser constatadas com a Política Nacional de Atenção Básica (PNAB), a qual determina a composição de uma "equipe mínima" de profissionais voltados para atenção à saúde da população de um determinado território adscrito, com o objetivo de ampliar a capacidade analítica e resolutiva diante dos casos de adoecimento nas comunidades, reconhecendo a importância de ações e intervenções realizada entre diferentes profissionais (BRASIL, 2012). Sendo assim, o SUS busca modelos de atenção que valorizem além da integralidade, a humanização do cuidado e as ações concentradas nas estratégias para prevenção e, principalmente, promoção de saúde (OLIVEIRA; BALARD; CUTOLO, 2013).

A formação e o trabalho multiprofissional e interdisciplinar voltados para a integralidade do cuidado em saúde têm destaque e relevância em diferentes contextos, pois 
a partir de documentos governamentais, produções científicas e em congressos e rodas de discussões nota-se o desejo de mudanças no modelo de atenção à saúde.

Diante do exposto, faz-se necessária uma estruturação e transformação na ordem de conhecimento voltado para o SUS e também de transformação de práticas voltadas a tais conhecimentos e necessidades da população. Nesse quesito os projetos do PRÓ-PET Saúde, em especial, o PET-GraduaSUS vêm a contribuir com a formação de futuros profissionais para atuação voltada para o contexto nacional contemporâneo. Sendo assim, o Programa de Educação pelo Trabalho para a Saúde - PET-Saúde, é uma das ações intersetoriais direcionadas para o fortalecimento de áreas estratégicas para o SUS, de acordo com seus princípios e necessidades, o programa tem parceria com a Rede Municipal, possibilitando bolsas para preceptores, tutores, professores, preceptores e alunos de diferentes cursos da saúde (FARHAT, et al., 2016).

Este trabalho diz respeito ao relato de experiência de acadêmicos de cursos da área da saúde com o processo de implementação do projeto PET-GraduaSUS que ocorre em parceria com a Secretaria Municipal de Saúde de um município do Vale do Itajaí. O projeto faz parte das ações voltadas à formação profissional contemplando os eixos e vetores do PRÓ-PET-Saúde e as Diretrizes Curriculares Nacionais vigentes (DCNs) para transformar o processo de produção de conhecimentos e de prestação de serviços voltados para o Sistema Único de Saúde (SUS) (FARHT et al., 2016; VIANA et al., 2016; RIBEIRO, et al., 2017).

Dessa forma, o GraduaSUS surge para consolidar esta integração, tendo como objetivos: a) promoção de mudança nas Diretrizes Curriculares Nacionais dos cursos da área de Saúde; b) qualificação das integrações ensino-serviço-comunidade dando acesso à articulação do Sistema Único de Saúde (SUS) com a Instituição de Ensino; c) unir projetos do Ministério da Saúde e Ministério da Educação, além de outros projetos locais ou regionais, para a integração ensino-serviço-comunidade; d) fortalecer a mudança e aproximação da graduação da saúde com o SUS (VIANA, et al., 2016).

Este trabalho tem como objetivo apresentar a experiência vivenciada por acadêmicos de graduação pertencente ao Centro de Ciências da Saúde de uma Universidade do Estado de Santa Catarina. Tal relato visa apresentar o processo de inicialização no projeto GraduaSUS, bem como as expectativas e os desafios enfrentados na perspectiva de estudantes. Será discutida a experiência na relação da teoria com a prática já no primeiro ano do curso, tendo em vista a integração ensino-serviçocomunidade. Acredita-se que esse relato trará contribuições significativas para a área da saúde, especialmente no que se refere à formação de profissionais voltados para a atuação no Sistema de Saúde Nacional. Espera-se, com esse trabalho, tornar públicas as experiências providas pelo GraduaSUS e fazer-se presente a relação entre a teoria e a prática dentro das Unidades Básicas de Saúde, envolvendo um debate crítico e construtivo sobre o tema. Deste modo, o relato torna-se extremamente relevante à Academia, visto que contribui para reflexões e futuras pesquisas, as quais possibilitem o elo entre educação, saúde e comunidade. 


\section{MATERIAL E MÉTODOS}

Este trabalho insere-se na modalidade de relato de experiência, tendo em vista a apresentação de uma experiência acadêmica vivenciada no primeiro ano de graduação pelos cursos de graduação na área da saúde. $O$ relato a ser apresentado diz respeito às atividades experienciadas durante a implementação do projeto GraduaSUS em uma Universidade do Estado de Santa Catarina. Tal projeto teve como participantes alunos de todos os cursos da área da saúde, mas este relato é constituído pela experiência na perspectiva de estudantes do curso de Psicologia, que ocorreu em conjunto com o curso de fisioterapia.

O cenário da experiência foi um município do Vale do Itajaí em Santa Catarina, mais especificamente, em uma Unidade Básica de Saúde (UBS), a qual é composta por duas Equipes de Estratégia de Saúde da Famíla. Para uma melhor inserção neste local, o projeto GraduaSUS possui um preceptor responsável pelos encontros. Geralmente, este preceptor é um(a) enfermeira(a)-chefe ou algum(a) residente que trabalha na Unidade. Nesse caso, a preceptoria esteve representada pela enfermeira chefe da Unidade. Os preceptores possuem como função possibilitar aos acadêmicos uma vivência prática, sendo inseridos na estrutura da Unidade e tendo contato com o cotidiano e usuários da mesma. Além de ter o apoio dos preceptores, os acadêmicos contam com a ajuda de professores, responsáveis por disciplinas teóricas nas quais as inserções na Unidade Básica de Saúde e o GraduaSUS estão presentes. Consequentemente, os preceptores e professores, em conjunto, possibilitam uma visão integral e interdisciplinar aos acadêmicos, relacionando teoria e prática.

Tal experiência diz respeito, portanto, a essas duas inserções no contexto da Atenção Básica em Saúde e de momentos de discussões teórico-práticas em sala de aula, ocorridos a cada semestre durante o ano de 2016. Fizeram parte dessa última etapa as discussões envolvendo a atividade intercursos e a orientação de produção de um relatório científico na modalidade de relato da experiência com articulação teórica.

Dessa forma, a metodologia utilizada foi composta por vivências ou inserções práticas voltadas à Atenção Básica à saúde, juntamente com reflexões e conhecimentos teóricos. Foram utilizadas rodas de conversa, discussão de casos e a abordagem de resolução de problemas, além de inserções práticas nas UBS. Primeiramente, são realizadas as preparações teóricas que os acadêmicos dentro da sala de aula, para em seguida, inserirem-se na Unidade Básica de Saúde. Consequentemente, são realizadas reflexões advindas das inserções, em conjunto da elaboração do relatório das mesmas. Por fim, é exposto o processo de compartilhamento das vivências obtidas com o projeto, que resultou em uma apresentação no Seminário Científico.

O Projeto GraduaSUS, por ter inserções diferenciadas em cada período ou semestre do curso, possui também objetivos diferentes. Para tanto, no primeiro período tem-se a finalidade de ampliar a concepção de sociedade e saúde daqueles que acabam de adentrar a Universidade. Estes são contemplados pela disciplina Psicologia da Saúde, 
a qual promove a discussão de diversos elementos sobre o SUS, desde a história de sua criação e suas gêneses, os movimentos populares e a participação social e, até mesmo, a atuação profissional no olhar da integralidade através de uma equipe multiprofissional, realizando-se ações interdisciplinares.

Após as inserções do primeiro período, as inserções do segundo período do curso surgem para agregar e potencializar os aprendizados daqueles que iniciaram suas trajetórias no Projeto GraduaSUS. Isto posto, a matéria de Ambientação Profissional II encarrega-se de debater com os alunos temas como Ética, Bioética, Humanização, Atenção Básica como estruturante do SUS e Epistemologia em Saúde.

Tendo em vista os objetivos de cada período, pretende-se com este trabalho relatar/refletir sobre as inserções e vivências das acadêmicas de Psicologia, proporcionadas pelo Projeto Pet GraduaSUS em parceria entre a Universidade e a Secretaria Municipal de Saúde, ocorridas durante o ano de 2016, em uma Unidade Básica de Saúde de um município do Estado de Santa Catarina.

\section{RESULTADOS E DISCUSSÕES}

Conforme mencionado anteriormente, os acadêmicos, desde o primeiro período do curso de Psicologia, entram em contato com a teoria do SUS e, por meio desse contato tiveram o conhecimento sobre a atuação multiprofissional. Após discussões e debates sobre o tema, conhecimento da equipe que a compõe e os projetos dedicados aos usuários, verifica-se a possibilidade de um contato abrangente com pessoas e grupos, ampliando a comunicação entre estes, retirando-os do isolamento e das relações de hierarquia, concretizando os ideais propostos pela Política Nacional de Humanização (BRASIL, 2012). Para tanto, serão apresentadas as inserções realizadas durante o primeiro e o segundo semestre do curso de graduação de Psicologia, que ocorreu em conjunto com alunos do curso de fisioterapia.

As inserções ocorridas no primeiro período tiveram a participação de cinco acadêmicos no primeiro semestre de 2016, as quais tinham como objetivos discutir concepções, determinantes sociais de saúde e a história do Sistema Único de Saúde. Assim sendo, este último foi instruído com um vídeo o qual mostrou a importância dos movimentos sociais para a constituição do sistema de saúde que utilizamos. Deste modo, notou-se que, da mesma forma o qual em 1988, movimentos estudantis e trabalhistas proporcionaram a Reforma Sanitária, com o intuito de criar um sistema no qual a saúde fosse um direito de todos e dever do Estado, atualmente é necessário o fortalecimento desses mesmos movimentos para reforçar e consolidar cada vez mais o Sistema Único de Saúde. Segundo Ceccim e Feuerwerker (2004) é evidente a urgência de movimentos sociais para uma reforma na educação, que possibilite responsabilidade acadêmicacientífica, agregando ética e humanização em sua atuação profissional.

Dando continuidade, após a apresentação do vídeo e discussões sobre este, o 
preceptor solicitou para que os acadêmicos falassem palavras que definiam, para cada um, o Sistema Único de Saúde. Palavras como: filas, mortes, falta de médicos e medicamentos apareceram para compor a ideia inicial dos estudantes. Porém, após debates teóricos em rodas de conversa, a equipe (preceptor e dois residentes) que estava com os acadêmicos mostrou-os a realidade do local e, também comentou pontos fortes e fracos do Sistema Único de Saúde.

Durante a conversa, percebeu-se que, como qualquer outra Unidade, esta também possui algumas falhas. Um dos significativos desafios do Sistema Único de Saúde do Brasil está em investir na formação de recursos humanos. Desafio esse que se concentra especialmente no que se refere à busca de atuações que contemplem a perspectiva da integralidade. Na formação dos profissionais na atualidade fica faltando, portanto, qualificação e atualização técnico-científica de profissionais da área da saúde, ancoradas nos princípios e diretrizes do Sistema Único de Saúde (SUS), especialmente no que concerne a estruturação do cuidado e a visão crítica acerca das demandas do meio sociocultural nacional. Formação essa que necessita estar em conformidade com o modelo contra hegemônico (CECCIM; FEUERWERKER, 2004; FERREIRA NETO, et al., 2016; MACHADO, et al., 2015; OLIVEIRA; BALARD; CUTOLO, 2013).

Entretanto, o destaque é para os pontos positivos, resultantes da eficácia do Sistema em conjunto com a Unidade Básica de Saúde ao promover um atendimento eficiente para a população daquele bairro, suprindo suas necessidades. Mesmo não sendo o principal objetivo desta inserção, os acadêmicos puderam conhecer como se dá o acolhimento nesta Unidade, como é feita a requisição para algum medicamento e, como as consultas dos usuários são agendadas, caso não se encaixe em uma emergência.

Através da conversa, foi possível concluir que, em sua grande maioria, os acadêmicos possuem uma visão distorcida do que o Sistema Único de Saúde realmente representa, pelo desconhecimento tanto no que se refere a ser usuário do SUS quanto no que concerne a ser profissional de saúde. Consequentemente, é notório o poder e influência que a mídia tem na vida da maioria da população brasileira, passando uma imagem, predominantemente negativa do SUS e das Unidades Básicas de Saúde.

Ressalta-se, nesse quesito, a importância dos Conselhos Municipais de Saúde, que são os principais canais de participação popular e possibilitam a proximidade da comunidade com a dinâmica dos serviços de saúde da Unidade e a integração com as demais organizações do bairro, sendo um componente estratégico da gestão participativa. É por meio deles que a população (junto com seus representantes) pode participar da gestão pública. Tal fato retoma os princípios básicos da Política Nacional de Humanização, que destaca a importância do protagonismo da população para com seus direitos e atuação na produção de sua própria saúde (BRASIL, 2012).

Após as vivências realizadas na sala de aula, as inserções no segundo período do curso, ocorreram no segundo semestre de 2016. Estas contaram com a participação de alunos de outros cursos da área da Saúde, em especial os estudantes Fisioterapia que estiveram presentes juntamente com a Psicologia, fator que agregou ainda mais os 
conhecimentos obtidos naquela manhã.

No primeiro momento, foi proposta uma dinâmica de familiarização com o preceptor e residentes da Unidade e com os demais colegas, na qual foi solicitada em que cada um tirasse um símbolo de uma caixa e, após, encontrasse a pessoa que estava com 0 respectivo par. Foi destinado aproximadamente cinco minutos para que cada um pudesse perguntar ao seu colega, o nome, idade, curso e um sonho. Após esta primeira etapa, a dupla teve que se apresentar e, indicar a próxima para compartilhar as informações obtidas no breve diálogo com o colega.

Em seguida, após as apresentações, foi entregue pelos preceptores dois relatórios, um a respeito da caracterização do território e outro que continha perguntas a serem feitas em uma entrevista com uma Agente Comunitária de Saúde (ACS) da UBS. Esta entrevista, realizada de maneira informal enquanto os acadêmicos conheciam o território em que a Unidade se encontra em uma visita guiada pelos preceptores e ACS, serviu de base para um melhor entendimento do bairro e sua população. Durante a caminhada, foi possível identificar o território e discutir os determinantes sociais de saúde de forma contextualizada, de maneira a aprofundar o que foi proposto nas primeiras inserções. Além do mais, nesta segunda inserção, foi realizada uma visita domiciliar a um usuário da UBS, junto aos acadêmicos e seu preceptor. Esta visita teve o objetivo de identificar a opinião do usuário acerca dos serviços prestados pela Unidade e de reconhecer a demanda do usuário e sua família para a utilização das atividades lá ofertadas.

Ao chegar de volta à UBS, os desafios, pontos fortes e fracos do SUS foram debatidos e, mais uma vez, a formação dos profissionais de saúde torna-se fator facilitador da implementação do Sistema como um todo. Relacionando os dados obtidos durante a visita domiciliar e, conhecimentos prévios, destaca-se como principal ponto negativo a dificuldade de agendar uma consulta com médicos especialistas (neste caso, com oftalmologista) e, como ponto positivo, o usuário frisou a alta qualidade do acolhimento na Unidade.

São muitos os desafios e de diversas ordens, mas parece que os recursos humanos são um dos destaques para o bom funcionamento da Política Pública em Saúde (FERREIRA NETO, 2016; OLIVEIRA; BALARD; CUTOLO, 2013). A ética e a humanização em saúde foram discutidas por meio da realização de visitas domiciliares. Neste trabalho fica evidente a importância da equipe de profissionais em saúde, especialmente o papel a ser executado pelo Agente Comunitário em Saúde (ACS), o qual é um elo de suma importância entre a comunidade e a Unidade, pois possui um maior vínculo com os usuários e, ainda, possibilita visitas domiciliares de forma amigável (BRASIL, 2012).

Ademais, o projeto PET GraduaSUS faz parte de um conjunto de atividades baseadas na educação profissional, em que estudantes de diferentes formações e de diversos períodos em suas graduações, mediados por professores dos diversos cursos do Centro de Ciências da Saúde, que, de maneira integrada, aprendem e interagem, visando a melhoria da qualidade no cuidado à saúde (FARHT et al., 2016; VIANA et al., 2016). Isto posto, ainda pode-se visualizar o elemento de integração entre ensino-serviço-comunidade 
de forma mais clara quando compreendida cada etapa da construção desta união. As inserções realizadas durante o ano de 2016, contêm a presença de uma vasta gama de saberes, concretizando a presença de elemento multiprofissional à ação interdisciplinar.

Tendo em vista discutir a formação profissional em saúde, proporcionada pelo projeto e, tendo como princípios a integralidade e a interdisciplinaridade na Atenção Básica em Saúde, este trabalho proporcionou aos acadêmicos um debate contextualizado e crítico, que se tornou fundamental para sua formação atendendo à realidade teórico-prática nacional. A integração ensino-serviço-comunidade proposta insere-se como forma imprescindível de experiência em conformidade com a prática de cada curso da área da saúde envolvido no processo.

Nessa integração, a complexidade do processo saúde-doença é apontada e são discutidos pontos teóricos importantes no que se refere aos modelos explicativos em saúde coletiva. As discussões versam sobre as proposições e epistemologias constantes nos modelos hegemônico e contra hegemônico, ou seja, no processo que envolve a compreensão de uma concepção biomédica e de uma concepção biopsicossocial em saúde (FERREIRA NETO, et al., 2016; MACHADO, et al., 2015; PUTTINI; JUNIOR; OLIVEIRA, 2010). As reflexões acerca de uma compreensão biopsicossocial para o processo saúdedoença indicam e fazem com que os alunos possam debater com seus professores e tutores sobre o modelo da determinação social da saúde, visto tanto teoricamente, quanto na prática da realidade social.

No que se refere à modalidade ensino, a possibilidade de já ter contato teoricamente com os princípios e diretrizes do SUS, bem como a discussão crítica da teoria possibilita aos acadêmicos inserções científicas concernentes à leitura, reflexões, como também na escrita técnico-científica, representada pela produção de um trabalho que foi apresentado em um evento da área. No que diz respeito ao elemento serviço e comunidade, a visualização destes a partir das inserções do(as) acadêmicos(as) realizadas nas Unidades Básicas de Saúde, servem de plano de fundo para a aplicação dos ensinos anteriormente disponibilizados dentro da sala de aula para os(as) acadêmicos(as) sobre a teoria do SUS. Deste modo, os conceitos aprendidos, como a Atenção Básica, integralidade, territorialização, dentre outros, são essenciais para a compreensão da forma em que se realiza o serviço (CECCIM; FEUERWERKER, 2004; FERREIRA NETO, et al., 2016; MACHADO, et al., 2015; OLIVEIRA; BALARD; CUTOLO, 2013).

Além disso, ao conhecer as atividades realizadas por aqueles que efetivam os serviços nas UBS, como os residentes e profissionais da saúde, torna-se possível associar, ainda mais, a teoria e a prática. Sendo assim, o ensino torna-se a base da compreensão dos serviços, que consequentemente, levará ao encontro com o elemento final desta composição: a comunidade.

A apropriação dos elementos tratados faz-se primordial no estabelecimento de uma relação com a comunidade - visto que ela está em contato direto com os serviços prestados pelo Sistema Único de Saúde e aqueles que o compõe. Deste modo, os conceitos entendidos previamente fazem-se presentes cada vez mais quando se adentra no SUS. 
Em relação à comunidade, é inconfundível visualizar a territorialização como um elemento extremamente presente. Os princípios do SUS, que se faziam existentes dentro das UBS, agora seguem adiante destas e encaminham-se às moradias dos usuários da saúde pública, materializando a integralidade.

\section{CONCLUSÕES}

Através dos conhecimentos adquiridos dentro da sala de aula, o Projeto Pet GraduaSUS possibilita que os aprendizados obtidos sejam visualizados na prática, entrando em contato direto com o SUS e as Unidades Básicas de Saúde. Sendo assim, os(as) acadêmicos(as) dos cursos da área de Saúde vivenciam a integralidade e participam de atividades com as equipes multiprofissionais que lá atuam.

Participar do programa PET-GraduaSUS constituiu-se como um desafio para os alunos pelo fato de entrar em contato com teorias, espaços práticos e a interdisciplinaridade desde o início da graduação. Notou-se que as diferentes visões dos estudantes dos cursos da área da Saúde confrontam-se em debates e compreensões de temas. Porém, ao perceber tal dificuldade, os acadêmicos puderam compreender que situações como estas podem de fato acontecer no cotidiano das equipes multidisciplinares que trabalham nas Unidades Básicas de Saúde. Dessa forma, destaca-se a importância do Projeto ao possibilitar o diálogo, já no primeiro período da graduação, com a multidisciplinaridade. Assim, é possível compreender a necessidade de trabalhar-se em uma equipe multiprofissional para obter uma visão integral do fenômeno.

Sendo assim, conclui-se que o Projeto PET GraduaSUS é de fato significativo para ampliar a visão dos futuros profissionais que atuarão no Sistema Único de Saúde. Os acadêmicos, após as inserções realizadas, percebem sua importância e papel na sociedade como profissionais da saúde. A teoria, mediada na sala de aula e a prática, vivenciada nas inserções, tornaram-se essenciais para esta visão. Além de perceber-se na sociedade, a mesma foi notada de forma diferenciada. $O$ contato com os usuários e o bairro acrescentaram compreensões de questões sociais que, apenas entrando no contexto, fazse presente sua importância - que é olhada pela Unidade Básica de Saúde e seus profissionais.

Devido à tamanha relevância científica e social destas inserções, os acadêmicos que participam das referidas atividades desejam passar mais tempo dentro da UBS com os profissionais e usuários, podendo assim identificar de forma mais aprofundada as dificuldades e facilidades de cada local, de modo a auxiliar a equipe a desenvolver melhorias e/ou aprimorar os serviços.

\section{REFERÊNCIAS}

AMANCIO FILHO, A. Dilemas e desafios da formação profissional em saúde. Interface 
(Botucatu), Botucatu, v. 8, n. 15, p. 375-380, Aug. 2004.

BRASIL. Ministério da Saúde. Secretaria de Atenção em Saúde. Departamento de Atenção Básica. Política Nacional de Atenção Básica. Brasília: Ministério da Saúde, 2012. Disponível em: <

http://dab.saude.gov.br/portaldab/biblioteca.php?conteudo=publicacoes/pnab />. Acesso em: 26 jun. 2016.

CECCIM, R. B.; FERUERWERKER, L. C. O quadrilátero da formação para a área da saúde: ensino, gestão, atenção e controle social. Physis, Rio de Janeiro, v. 14, n. 1, p. 4165, Jun. 2004.

FARHAT, E. M. P. et al. Ações da Univali no programa de reorientação da formação em saúde: PRÓ e PET - Saúde. In: FARHAT, Eleide Margarete Pereira; DITTRICH, Maria Glória (orgs). EDUCAÇÃO E SAÚDE: políticas públicas e vivências dialógicas. Itajaí: Ed. da Universidade do Vale do Itajaí, 2016.

FERREIRA NETO, J. L. et al. Integralidade, condições de oferta de serviços e processo de trabalho de Equipes de Saúde da Família em Belo Horizonte. Saúde debate, Rio de Janeiro, v. 40, n. 111, p. 179-192, Dec. 2016.

MACHADO, J. de F. F. P. et al. Educação Permanente no cotidiano da Atenção Básica no Mato Grosso do Sul. Saúde debate, Rio de Janeiro, v. 39, n. 104, p. 102-113, Mar. 2015.

OLIVEIRA, I. C.; BALARD, C. R.; CUTOLO, L. R. A. Formação profissional em saúde: integralidade em perspectiva. Sau. \& Transf. Soc., Florianópolis, v. 4, n. 1, p. 69-72, 2013.

PASSOS, E.; CARVALHO, Y. M. A formação para o SUS abrindo caminhos para a produção do comum. Saude soc., São Paulo, v. 24, supl. 1, p. 92-101, Jun. 2015.

PEREIRA, S. C. L. et al. Percepção de monitores do PET-Saúde sobre sua formação e trabalho em equipe interdisciplinar. Interface (Botucatu), Botucatu, v. 19, supl. 1, p. 869878, 2015.

PUTTINI, R. F.; JUNIOR, A. P.; OLIVEIRA, L. R. de. Modelos explicativos em Saúde Coletiva: abordagem biopsicossocial e auto-organização. Physis Revista de Saúde Coletiva, Rio de Janeiro, v. 20, n. 3, p. 753-767, 2010.

RIBEIRO, M. A. et al . Oficina Mapa Vivo na atenção básica: estratégia de planejamento local ao combate ao Aedes aegypti. Saúde debate, Rio de Janeiro, v. 41, n. spe2, p. 338346, Jun. 2017.

ROCHA, P. R. da; DAVID, H. M. S. L. Determinação ou Determinantes? Uma discussão com base na Teoria da Produção Social da Saúde. Rev Esc Enferm USP, São Paulo, v. 49, n. 1, p. 129-135, 2015.

VERDI, M.; CAPONI, S. Reflexões sobre a promoção da saúde numa perspectiva bioética. Texto e Contexto Enfermagem, Florianópolis, v. 14, n. 1, p. 82-88, Mar. 2005.

VIANA, S. B. P. et al. Integração ensino-serviço-comunidade: propostas para mudança curricular dos cursos da área da saúde - Univali. In: FARHAT, Eleide Margarete Pereira; DITTRICH, Maria Glória (orgs). EDUCAÇÃO E SAÚDE: políticas públicas e vivências 
dialógicas. Itajaí: Ed. da Universidade do Vale do Itajaí, 2016. 